\title{
Behaviour of steel reinforced concrete beam-column joints
}

\author{
I. Montava, A. Gonzalez, R. Irles \& J. C. Pomares \\ Universidad de Alicante, \\ Departamento de Ingeniería de la Construcción, Spain
}

\begin{abstract}
A composite structure with steel reinforced concrete, SRC, has the strength of reinforced concrete and the ductility of steel, meaning that appropriate design can achieve high seismic resistance capacity.

The present investigation shows the results and conclusions obtained from analyzing the strength and ductility of three different joints of a structural frame tested with increasing loading and unloading cycles, one with Reinforced Concrete, RC, another with Steel reinforced concrete, SRC, and a third with only reinforced concrete with the same strength capacity as the SRC section.

We are able to give hyperstatic and isostatic structures sufficient failure warning capacity, significant ability to dissipate energy and adequate protection against fire.
\end{abstract}

Keywords: reinforced concrete structures, steel reinforced concrete, ductility, structures, SRC, HAA, joint, earthquake resistant structure, steel.

\section{Introduction}

In recent decades there have been numerous studies aimed at determining the seismic behaviour of reinforced concrete structures, metal structures and composite structures.

Composite structures achieve similar rigidity to concrete structures and similar ductility to steel structures, [1], with metal sections being necessary to protect against fire. Reinforced concrete structures with completely embedded profiles significantly increase energy dissipation with adequate fire protection [2] This study attempts to understand the behaviour of reinforced concrete structures with embedded metal profiles, known in English as SRC (steel reinforced 
concrete). SRC is a structural system able to combine the strength and stiffness advantages of reinforced concrete structures with the high ductility of steel structures, high fire resistance, high energy absorption capacity and simple, costeffective implementation acceptable to most builders and developers in the sector.

Since the Kanto earthquake (1923), which caused most fatalities of those known in Japan until the last Hounsu Coast earthquake (2011), the largest known magnitude at 8.9 degrees on the Richter scale, a type of composite construction system has been used in Japan for most of the structures of buildings over seven stories high [3].

The surprising seismic resilience of buildings in Japan is mainly due to the systematic use of profiles embedded in concrete structures and the use of energy dissipation by applying the Japanese seismic regulations [4]. The earthquake off the Japanese Hounsu coast on March $11^{\text {th }} 2011$ showed the excellent seismic behaviour of buildings built in recent years compared with the destruction caused by the tsunami provoked by the earthquake. Also surprising is the scant acceptance and diffusion of the structural system of metal sections embedded in reinforced concrete structures in European buildings up to now. Eurocode 4 refers to the calculation of this structural system [5].

It is true that the seismic forces are much higher in Japan, where structures must withstand earthquakes of magnitude seven or greater, but in certain unique buildings and especially those used by the public, it is essential to ensure the structural resistance to seismic action not covered by our current regulations. Hospitals, emergency centres, buildings, fire-stations, ambulance parks, power stations, schools and other buildings, should be designed to withstand disasters of varying magnitude, taking into account return periods higher than normally considered.

This structural system can increase little the overall cost of the work, compared with the importance of ensuring the structural strength demanded by severe earthquake activity.

\section{Study procedure}

A number of preliminary tests of the material used for the manufacture of prototypes were carried out to identify the real strength of the material. The ultimate resistance is much greater than expected resistance. The elastic limit was used to calculate resistance (Table 1).

Table 1: $\quad$ Material properties used in prototype 4 - SRC.

\begin{tabular}{|c|c|c|c|c|}
\hline Concrete & HA-25/F/20/I & Ac & $\begin{array}{l}\text { Fck=25 } \\
\mathrm{N} / \mathrm{mm}^{2}\end{array}$ & Fce $=31,58 \mathrm{~N} / \mathrm{mm}^{2}$ \\
\hline Steel reinf. & B-500-SD & As & $\begin{array}{c}\mathrm{Fsk}=500 \\
\mathrm{~N} / \mathrm{mm}^{2}\end{array}$ & $\mathrm{Fse}=511 \mathrm{~N} / \mathrm{mm}^{2}$ \\
\hline Structural Steel & HEB-100-S275 & $\mathrm{Aa}$ & $\begin{array}{c}\text { Fak }=275 \\
\mathrm{~N} / \mathrm{mm}^{2}\end{array}$ & $\mathrm{Fae}=335 \mathrm{~N} / \mathrm{mm}^{2}$ \\
\hline
\end{tabular}




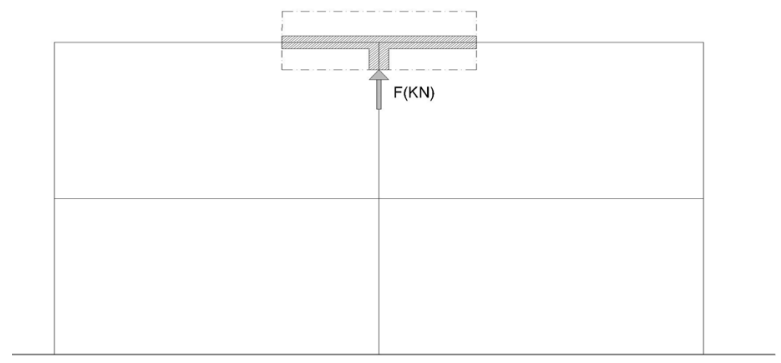

Figure 1: Single beam-column joint.

Loading and unloading tests with movement control were carried out (Fig. 2) on each of the prototype to breakage, using the laboratory test rig in the Department of Construction Engineering at the University of Alicante (Fig. 3).

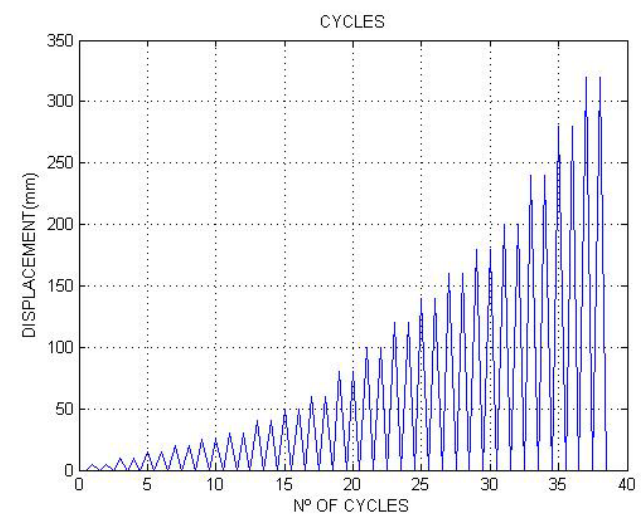

Figure 2: Loading-unloading cycles.
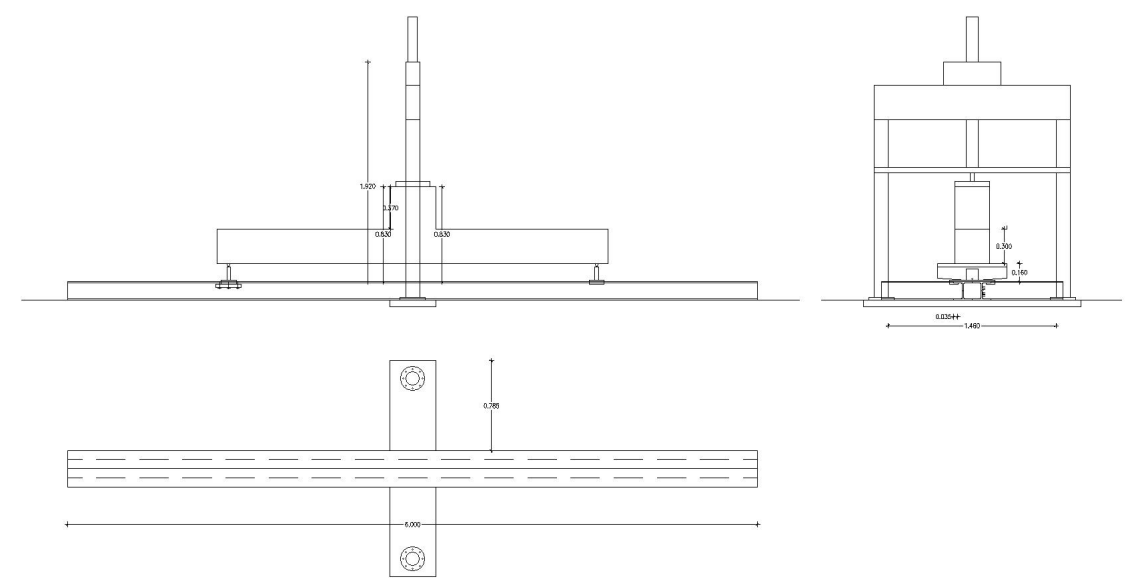

Figure 3: Laboratory test rig. 
The initial prototypes 1 and 2 were used to adjust the following prototypes to improve the design and calibrate the tests. The budget of the SRC joints is higher but the estimated budget on a $100 \mathrm{~m}^{2}$ rig (Table 2 ) is equalled by reducing the proportion of metal profiles in the structure as a whole and using mass-produced metal joints.

Table 2: $\quad$ Summary of the prototypes tested and data obtained.

\begin{tabular}{ccccccc}
\hline Prototype & & Cross-section & Steel & Steel section & $\begin{array}{c}\text { Joint } \\
\text { Price }\end{array}$ & $\begin{array}{c}\text { Estimated } 100 \\
\mathrm{~m}^{2} \text { cost }\end{array}$ \\
\hline P03 & RC & $300 \times 250$ & $4 \varnothing 12$ & - & $90 \mathrm{E}$. & $75 \mathrm{E} / \mathrm{m}^{2}$ \\
P04 & SRC & $300 \times 250$ & $4 \varnothing 12$ & HEB-100 & $150 \mathrm{E}$. & $85 \mathrm{E} / \mathrm{m}^{2}$ \\
P05 & RC & $300 \times 250$ & $2 \varnothing 16$ & - & $120 \mathrm{E}$. & $80 \mathrm{E} / \mathrm{m}^{2}$ \\
\hline
\end{tabular}

This is a simple 3-bar joint (Fig. 1). RC prototype 3 is made with conventional reinforcement, SRC prototype 4 (Fig. 4), keeps the same reinforcement and cross-section and concrete, with the metal profile added to identify the increase in ductility and strength. RC prototype 5 is designed with the ultimate strength of prototype 3 .

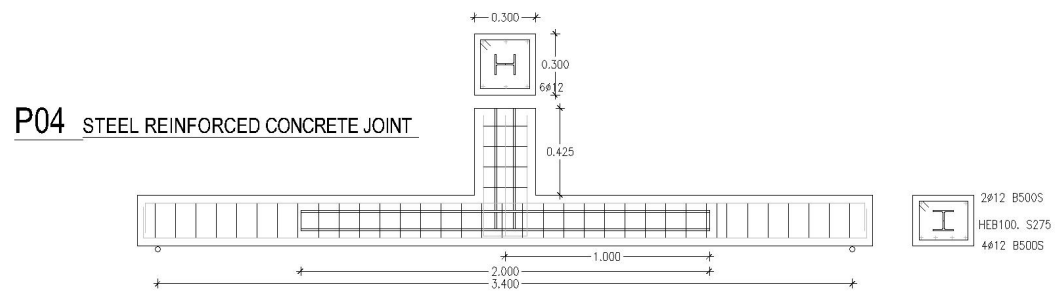

Figure 4: $\quad$ SRC prototype 4 tested.

The test results show the hysteretic behaviour in the load-deflection diagrams, and are analyzed in detail below.

\section{Analysis of results}

\subsection{Overview}

Figures 5 and 6 show the results for the three prototypes in a time-deflection diagram, already showing the increased strength and ductility between RC Prototype 3 and SRC Prototype 4.

They also show the different slopes and elastic and permanent deflections.

The RC prototype 3 is in domain 2 of deformation [6], and with little reinforcement obtains a cross-section with ductile failure. The final rupture of prototype 3 is a quick break, with the reinforcement under stress finally breaking and destroying the structure (Fig. 7).

Ultimate deformation is reached with total rupture of the steel. 


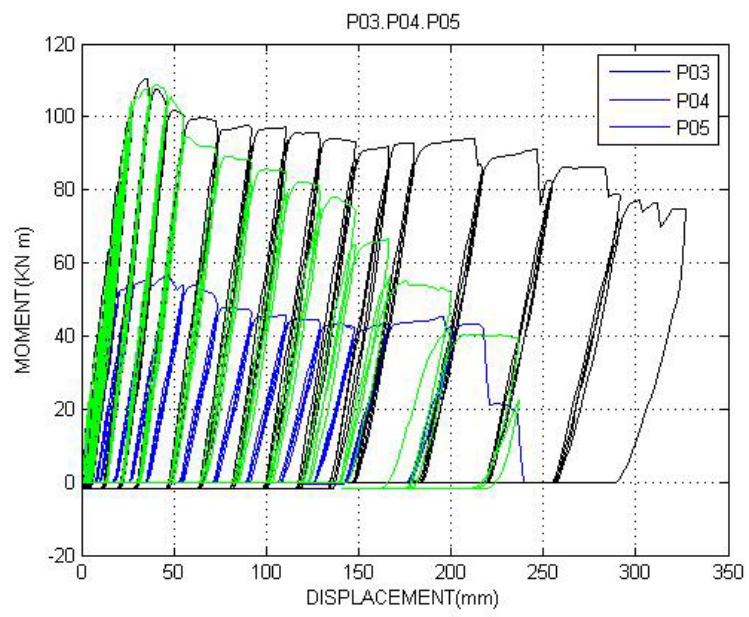

Figure 5: $\quad$ M-D complete graph of P03-P04-P05.

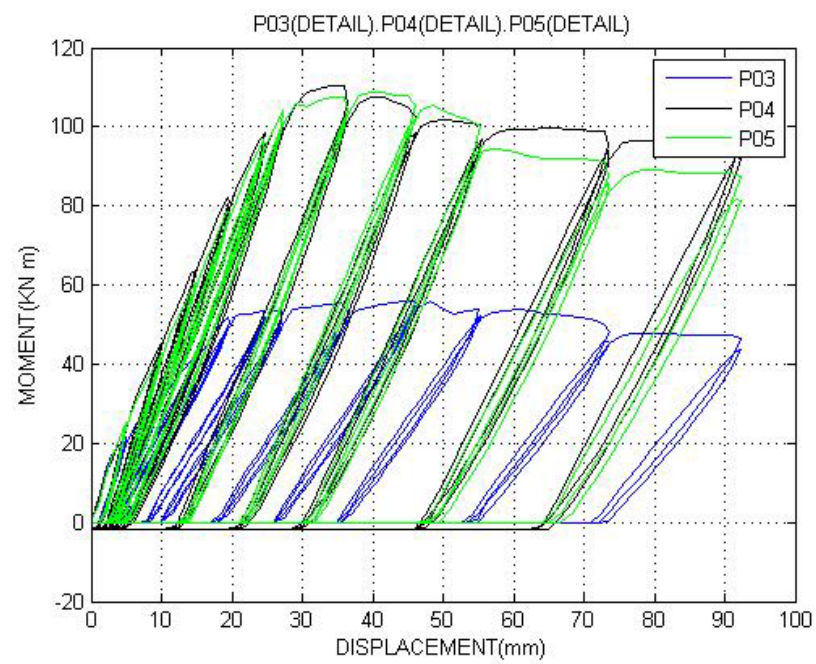

Figure 6: $\quad$ M-D details of P03-P04-P05.

With the SRC prototype 4 there is a break with much higher deformations. Once the concrete ruptures, the structure continues being deformed as if it were a metal frame, so very high deformations can be obtained, given the high ductility of steel metal profiles and the general confinement of the profile, which only disappears locally at the cross-section break (Fig. 8). Given the deformations achieved, the test was stopped with the cross-section maintaining high resistance, so that the ultimate deformation achieved occurred with the partial rupture of the cross-section in the plastic hinge stage, still with significant resistance capacity. 


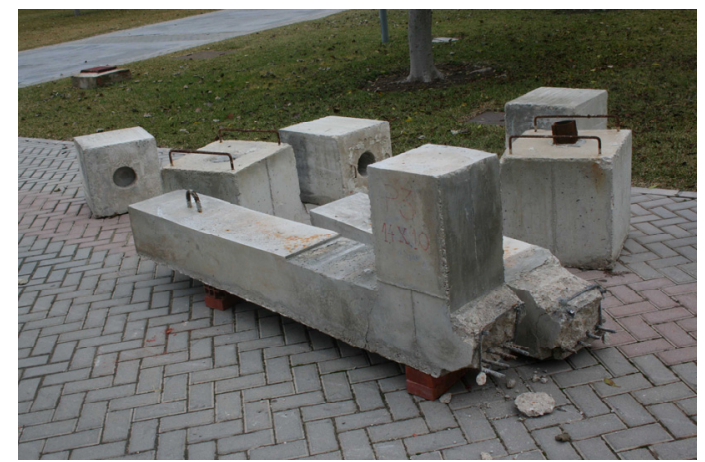

Figure 7: $\quad$ Photograph of the ultimate rupture of prototype 3.

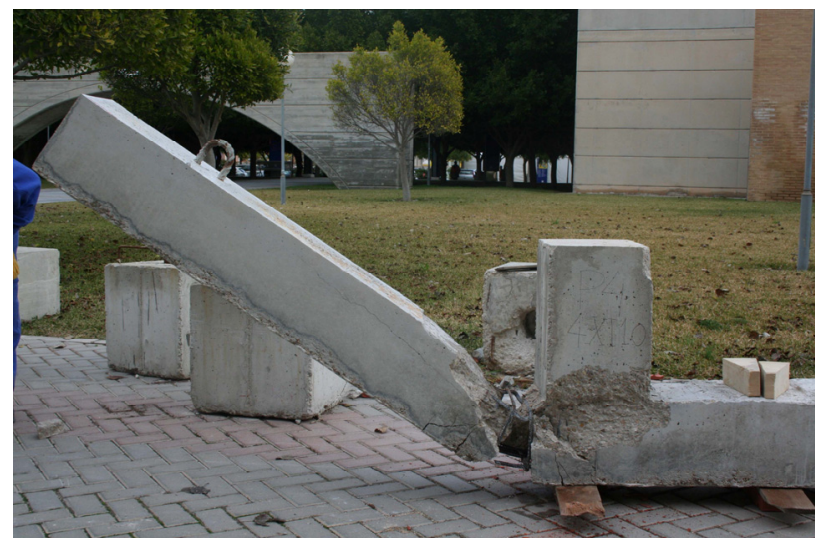

Figure 8: $\quad$ Photograph of the ultimate rupture of prototype 4.

Steel reinforced concrete Structures consist of three different materials. By progressively increasing the load, we find different stages of resistance of the cross-section. In structures, joint ductility allows the redistribution of loads and the dissipation of seismic energy. The high ductility that steel gives to reinforced concrete joints allows the structure to offer a capacity for plastic adaptation that prevents the appearance of excessive stress states, not explicitly calculated in general.

$\mathrm{RC}$ prototype 5 is designed with the ultimate strength of SRC prototype 4, but without the metal profile, so as to compare the difference in ductility between the two structures (Fig. 9).

The rupture occurs in domain 3, corresponding to the total compression fracture of concrete. The reinforcement broke by compressive buckling. 


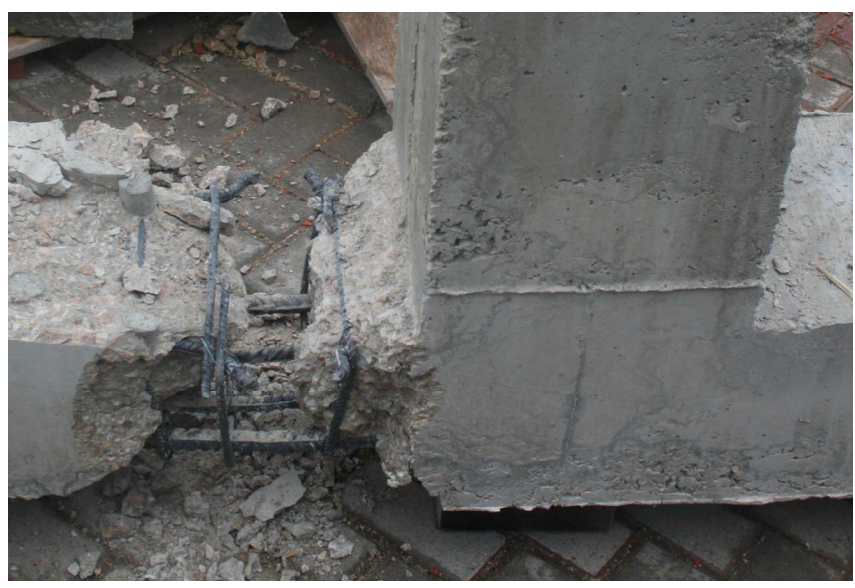

Figure 9: $\quad$ Photograph of the ultimate rupture of prototype 5.

\subsection{Calculation of the resistance of the SRC section}

With reinforced concrete structures, the following stress states can be identified as the loads applied are progressively increased: (Fig. 10).

1. - Elastic phase. The concrete has not been fully cracked and the section is behaving correctly. The sections are arranged according to the classical linearelastic behaviour and, in this case, the neutral axis passes through the centre of gravity of the homogenised section of the concrete and steel.

2. - Crack phase. The concrete most under stress reaches its tensile strength limit. The crack propagates and the stresses that the concrete stops resisting are absorbed by the structural steel and reinforcement, whose stress increases sharply. The neutral axis shifts towards the top flange of the metal profile, with the metal profile under stress. [7].

3. - Pre-break phase. The metal section still retains deformation capacity at this stage, meaning that the structure can continue to absorb energy before rupture.

4. - Metal profile break phase. Once the concrete loses all its strength, and the reinforcement under stress breaks, the section only resists with the metal profile.

With SRC structures, the most widely used and convenient method for calculating the ultimate strength is the method of superimposition of resistances, including the resistance capacity of three different materials, concrete, steel reinforcements and metal profiles, each with their own deformations.

Eurocode 4 describes a simplified method for calculating embedded steel sections completely covered by concrete to calculate the strength of sections subjected to flexion and compression. The calculation process consists of situating the neutral axis by force equilibrium equations and assessing the last moment the section resists.

With Prototype 4 the neutral axis in the flange of the profile (Fig. 11). 


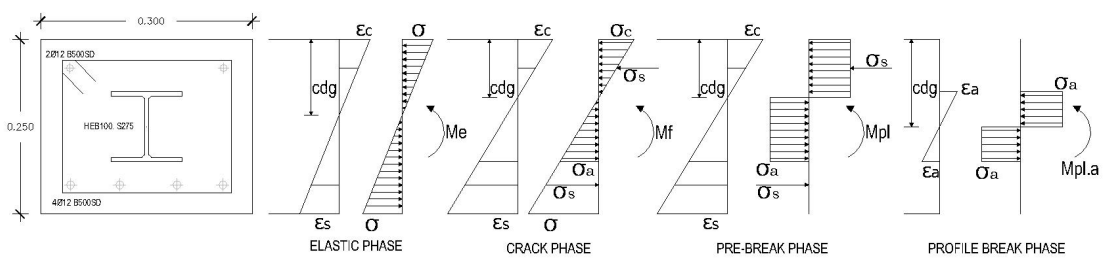

Figure 10: $\quad$ Stress states in concrete and steel under increasing load.

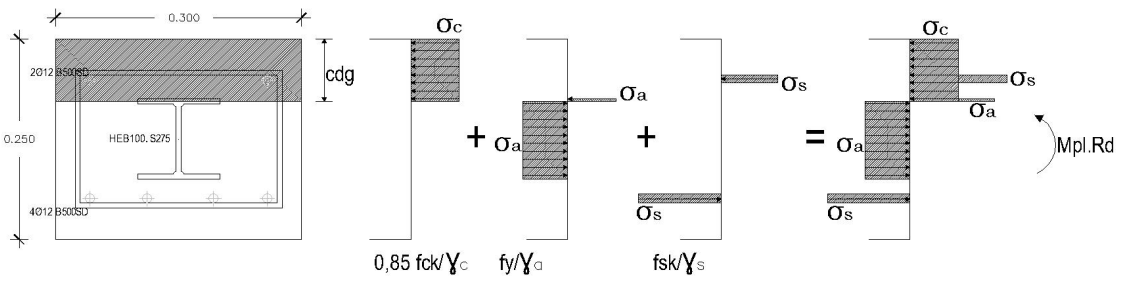

Figure 11: $\quad$ Stress state in pre-break for concrete and steel.

\subsection{Energy aspects}

The following chart summarizes the experimental results:

Defining the energy absorbed by deformation as the energy absorbed by the structure in the loading process and evaluating it as the area beneath the loaddeflection curve [8], we have:

$$
\text { Absorbed energy: } \mathrm{U}=\mathrm{W}=\int_{0}^{\Delta u} F(\Delta) d \Delta
$$

The elastic deformation energy is recovered in the process of loading and unloading when we are in the elastic range (Fig. 6). In the plastic phase most of the energy dissipates, with Table 3 showing the values for the final deflection of each prototype.

From the deflections obtained in the elastic regime we can identify the inertia of the sections (2), whose results are also shown in Table 3:

$$
\text { flech } a=f=\frac{P L^{3}}{48 E I}
$$

Table 3: $\quad$ Summary of the prototypes tested and data obtained.

\begin{tabular}{ccccccc}
\hline Prototype & & $\mathrm{KN}$ & $\mathrm{KN} \mathrm{m}$ & $\begin{array}{c}\text { Defor. } \\
\mathrm{mm}\end{array}$ & $\begin{array}{c}\text { Elastic } \\
\text { Energy }\end{array}$ & $\begin{array}{c}\text { Energy } \\
\text { absorbed }\end{array}$ \\
\hline P03 & RC & 73 & 55 & 220 & $10,863 \mathrm{~cm}^{4}$ & $10.31 \mathrm{KN} \mathrm{m}$ \\
P04 & SCR & 146 & 110 & 330 & $14.557 \mathrm{~cm}^{4}$ & $42,46 \mathrm{KN} \mathrm{m}$ \\
P05 & RC & 146 & 110 & 230 & $14.557 \mathrm{~cm}^{4}$ & $17,41 \mathrm{KN} \mathrm{m}$ \\
\hline
\end{tabular}


From the results we can deduce that the inertia of the SRC sections with metal embedded increases by $34 \%$ compared to the inertia of reinforced concrete sections in elastic range, with the increase in the slopes in Graph 11 being in elastic range.

The use of these joints in conventional reinforced concrete structures reduces the reinforced concrete sections by increasing the ductility of the structure, reducing labour demands by using less reinforcement, being easier to concrete and significantly increasing seismic safety. If the joints are produced industrially, their cost is greatly reduced, meaning that we estimate there to be almost no increase in cost over reinforced concrete structures.

\section{Conclusions}

The following conclusions are drawn from the experimental results presented:

1. - The absorbed energy to rupture in the SRC prototype is triple that for RC to equal strength, and equal reinforcement increases four times with the embedded metal profile added. (Table 4)

2. - The resistance of Steel reinforced concrete sections, SRC, is nearly twice the tensile strength of the reinforced concrete section, $\mathrm{RC}$, without the metal profile (Fig.12).

3. - The successive slopes of the loading-unloading graph are higher and more consistent in the prototype in the SRC prototype than in the RC prototype, which is less rigid (Fig. 6).

4. - The successive slopes of the loading-unloading graph, measuring stiffness, than are greater in the elastic zone in the plastic zone (Fig. 6)

5. - The inertia of the SRC sections is greater than that of the RC sections, the increase being greater than that due to the principal inertia of the metal profile. (Table 3).

6. - The ultimate deformation is much higher in SRC structures, which behave like metal structures with near fracture deformations, compared to RC structures, which have a fragile ultimate rupture. This means that the ductility of the SRC structure can be nearly double that of the RC structure (Fig. 12)

7. - Steel reinforced concrete Structures, SRC, significantly improve ductility and resistance and can dissipate a lot of energy, making them safer and more resistant to seismic activity than reinforced concrete, RC.

8. - In the light of these results, it would be interesting to consider generalising the reinforcement with metal profiles embedded in the joints of Reinforced Concrete structures to obtain more earthquake resistant structures with adequate fire resistance, especially in public and emergency service buildings in which high-seismic safety should be guaranteed. 


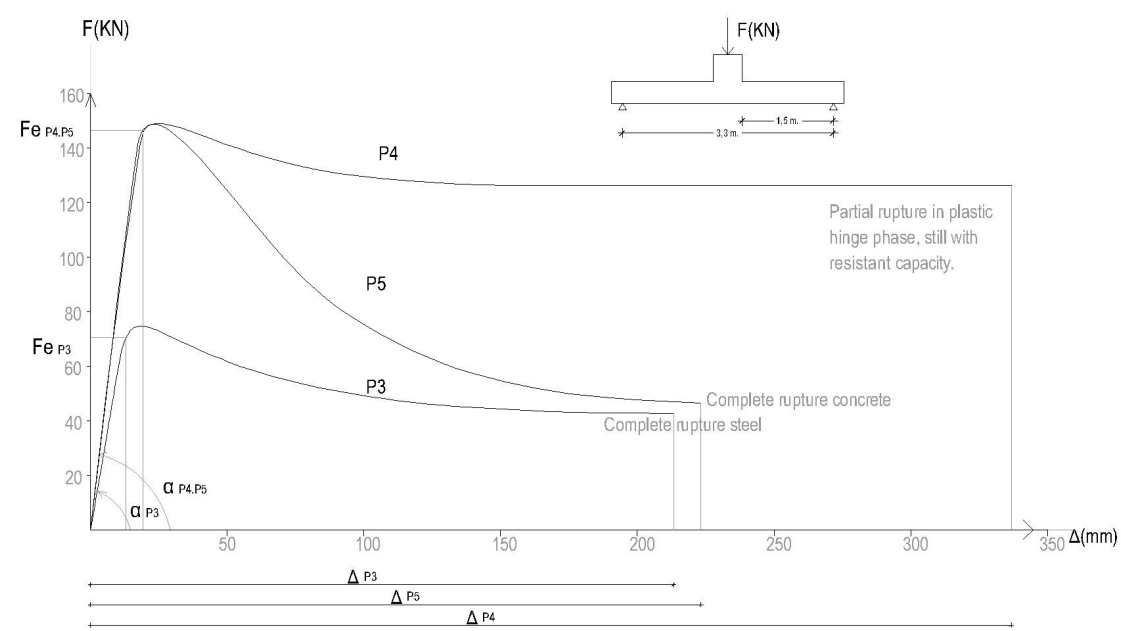

Figure 12: Graph summarising the test results.

\section{Acknowledgements}

The studies presented in this paper were made possible thanks to the financial support of the Department of Construction Engineering at the University of Alicante. The authors gratefully acknowledge this support.

\section{References}

[1] Beatriz Gil Rodriguez, Metodología práctica para el diseño de pórticos de estructura mixta con uniones semi-rígidas. Tesis Doctoral. Universidad de Navarra, 2006.

[2] Cheng-Cheng Chen, Keng-Ta Lin, Behaviour and strength of Steel reinforced concrete beam-column joints with two-side force inputs, Journal of Constructional Steel Research, 65.pp. 641-649, 2009.

[3] Hiroshi Kuramoto, Seismic Design Codes for Buildings in Japan, Journal of Disaster ResearchVol.1No.3, 2006.

[4] Wakabayashi, Minoru. Martinez Romero, Enrique, Diseño de estructuras sismorresistentes, McGraw-Hill, pp.180-189, 1988.

[5] Eurocode 4. Proyecto de estructuras mixtas de hormigón y acero, 1994.

[6] EHE-08-. Instrucción de Hormigón Estructural, 2008.

[7] Benito Hernández, C., Nociones de cálculo plástico, Editorial Rugarte, S.L., Madrid, pp 24-25, 1975.

[8] Hiroshi Akiyama, Metodología de proyecto sismorresistente de edificios basada en el balance energético. Editorial Reverté. S.A., 2003. 